\title{
The Impact of the Essential Fatty Acids (EFA) in Human Health
}

\author{
Alberto Krayyem Arbex ${ }^{1,2 *}$, Vagner Rosa Bizarro', Julio Cesar Salles Santos'1, \\ Lis Marina Mesquita Araújo', Ana Luísa Conceição de Jesus', \\ Minelli Salles Alves Fernandes ${ }^{1}$, Marcela Miranda Salles', \\ Denise Rosso Tenório Wanderley Rocha ${ }^{1}$, Aline Marcadenti ${ }^{3,4}$ \\ ${ }^{1}$ Division of Endocrinology, Faculdade IPEMED de Ciências Médicas (IPEMED), Rio de Janeiro, Brazil \\ ${ }^{2}$ Visiting Scientist of the Harvard School of Public Health, Harvard University, Boston, USA \\ ${ }^{3}$ Postgraduate Studies Program in Cardiology, Instituto de Cardiologia/Fundação Universitária de Cardiologia \\ do Rio Grande do Sul (IC/FUC), Porto Alegre, Brazil \\ ${ }^{4}$ Department of Nutrition, Universidade Federal de Ciências da Saúde de Porto Alegre (UFSCPA), Porto Alegre, \\ Brazil \\ Email: albertoarbex@gmail.com
}

Received 30 June 2015; accepted 26 July 2015; published 29 July 2015

Copyright (C) 2015 by authors and Scientific Research Publishing Inc.

This work is licensed under the Creative Commons Attribution International License (CC BY). http://creativecommons.org/licenses/by/4.0/

(c) (i) Open Access

\section{Abstract}

Linoleic (LA) and $\alpha$-linolenic acids (ALA) are considered essential fatty acids (EFA) because they are not produced by the human body. This way, EFAs sources must come from the diet. The primary dietary source of $\mathbf{n}-\mathbf{3}$ fatty acids is ALA, found in seeds and seed oils. Other important sources are fish oils such as tuna, salmon and herring. Currently, numerous studies suggest possible benefits of essential fatty acids in human health, such as in cardiovascular, cognitive and eye health, and also during pregnancy and childhood. This paper also discusses the impact of fatty acids in human metabolism, and the available evidence regarding its risks. It addresses the relevant debate regarding a general ban of trans fatty acids (TFA) from the world food market, because of the cardiovascular risks associated with its consumption.

\section{Keywords}

Fatty Acids, Linoleic Acid, Alpha-Linolenic Acid, Cardiovascular Health, Trans Fatty Acids

\section{Introduction}

The lipid components, especially the fatty acids, are present in various life forms, playing important roles in the ${ }^{*}$ Corresponding author.

How to cite this paper: Arbex, A.K., Bizarro, V.R., Santos, J.C.S., Araújo, L.M.M., de Jesus, A.L.C., Fernandes, M.S.A., Salles, M.M., Rocha, D.R.T.W. and Marcadenti, A. (2015) The Impact of the Essential Fatty Acids (EFA) in Human Health. Open Journal of Endocrine and Metabolic Diseases, 5, 98-104. http://dx.doi.org/10.4236/ojemd.2015.57013 
structure of cell membranes and metabolic processes. Families of omega-3 (w-3 or n-3) and omega-6 (w-6 or n-6) fatty acids consist of polyunsaturated fatty acids (PUFAs-Polyunsaturated Fatty Acids) containing 18 to 22 carbons. The designation "omega" is related to the position of the first double bond, counting from the end methyl group of the fatty acid molecule. The n-3 fatty acids have the first double bond between the third and the fourth carbon atom, whereas n-6 fatty acids have the first double bond between the sixth and seventh carbon atom. The main n-3 fatty acids are the $\alpha$-linolenic acid (ALA) 18:3, the eicosapentaenoic acid (EPA) 20:5 and the docosahexaenoic acid (DHA) 22:6, whereas the main n-6 fatty acids are the linoleic acid (LA) 18:2 and the arachidonic acid (AA) 20:4 [1].

Among the main functions of the fatty acids are energy storage, the composition of cellular membranes and being precursor of substances such as prostaglandins (PGs), thromboxanes and leukotrienes. The number and position of double bonds determine the physical and chemical properties of PUFAs. Families of n-6 and n-3 have different physiological functions and act together to regulate biological processes [1]-[3].

LA and ALA are essential fatty acids (EFA-Essential Fatty Acids) because the human body cannot produce them, so that the EFAs must be obtained from the diet. LA and ALA can be elongated and desaturated by an enzymatic system to produce DHA and EPA from vegetable oils from food, but this occurs in a low percentage [1]. Researchers also note that the use of EFAs and PUFAs such as biological markers for the evaluation of fat consumption is of great importance, because of their fundamental role in human health.

\section{Sources of Essential Fatty Acids}

The primary dietary source of n-3 fatty acids is ALA from seeds and seed oils. Linseed oil derived from flax seed (Liniun usitatissimun) is the richest available source of ALA, which is converted in the body to EPA and DHA. Other sources include canola, soybean, walnut and plants with dark green leaves, whilst n-6 fatty acid is found in vegetable oils such as corn, sunflower, and soybean [4].

EPA and DHA can be obtained by diet through various sources, including [5]:

a) Marine: the richest sources of n-3 are fish and fish products. Fish oils such as tuna, salmon and herring have estimated levels between 862 to $1840 \mathrm{mg}$ of EPA and DHA for each $100 \mathrm{~g}$. DHA is the major n-3 PUFA and it is noteworthy that most popular varieties of fish such as cod and clams, shrimp, crabs and oysters have a lower amount of DHA.

b) Earth: meat products are a poor source of EPA and DHA. However, all animals have n-3 PUFAs as part of cell membrane phospholipids, reaching levels close to $0.40 \mathrm{mg}$ for each $100 \mathrm{~g}$ of meat. In the context of low consumption of fish, the cow meat, pig, lamb, and poultry may contribute with small amounts of DHA.

c) Fortified foods: in addition to foods that naturally contain EPA and DHA, there is a growing movement in the market to enrichen industrialized foods with n-3 PUFAs, especially DHA. Some forms of enrichment of foods with n-3 are: 1) supplementation of animals by feeding n-3 PUFAs, enriching their tissues; 2) modification of oils (oil microencapsulation), provided for instance from algae and vegetable oils genetically modified; and 3) plant sources available, for instance, for the fortification of infant formula.

\section{Metabolism of Essential Fatty Acids}

Through an efficient enzymatic process, LA and ALA can be elongated and dessaturated into the functionally important longer chain n-6 and n-3 fatty acids. ALA (18 carbons) can be converted into a small amount of EPA (20 carbons) and even less DHA (22 carbons). Approximately $0.2 \%$ to $5 \%$ of ALA converts to EPA, and just $1 \%$ converts to DHA [6] [7].

EPA and DHA are molecular precursors to a family of eicosanoids that have anti-inflammatory, antithrombotic, antiarrythmic, and vasodilatory proprieties. On the other hand, LA is converted to AA, which is the precursor to a different group of eicosanoids that have proinflammatory and prothrombotic proprieties. N-3 and n-6 fatty acids compete for the same enzymes (delta- 5 and delta- 6 desaturase) for conversion into the longer-chain n-6 and n-3 fats; this competition is biologically important because the eicosanoids derived from both n- 6 AA and n-3 EPA and DHA have directly opposing effects [4].

N-26 fatty acids (FA) are metabolic products from AA and in higher levels may contribute to the formation of thrombi and atheromas, the development of allergic and inflammatory disorders (particularly in susceptible people) and cell proliferation. Dietary EPA and DHA can replace previous n-26 FA in cell membranes, especially those of platelets, erythrocytes, neutrophils, monocytes and liver cells. EPA can also replace AA in phos- 
pholipid bilayers, in addition to being a competitive inhibitor of cyclooxygenase-which reduces the production of many inflammatory mediators; DHA is able to inhibit platelet aggregation by reducing the affinity of platelet xA2/PGH2 receptor for its ligand [8].

High intake of LA from vegetable oils been shown to inhibit the conversion of ALA to the longer chain EPA and DHA. Because of the health-promoting effects of the n-3 EPA and DHA and the relatively low rate of conversion from ALA, both are considered "conditionally essential fatty acids." Currently, there is a scientific consensus that adequate intake of fish is important for the prevention of many common chronic disease states [9]. In addition, a large body of scientific evidence suggests that maintaining a balanced ratio of n-6 to n-3 fatty FA is essential for optimal health.

\section{Benefits of Essential Fatty Acids}

\subsection{Cardiovascular Health}

A high fish consumption may reduce the mortality caused by coronary artery disease. In the DART study, a 30\% reduction of acute coronary syndrome was reported in patients randomly designated to consume fatty fish twice per week [10]. EPA and DHA may decrease dysrhythmias, sudden death and the rate of atherosclerosis, as well as slightly lower blood pressure. Hence, the American Heart Association (AHA) has recommended the consumption of fatty fish ( $\geq 2$ portions/week) or fish oil as a complimentary therapeutic strategy to reduce cardiovascular diseases [9] [11]. n-3 reduces serum triglycerides levels (TG); therefore, it is not known how much of the cardiovascular benefits are a result of the TG-lowering effects caused by the n-3, and how much of it is related to TG-independent effects [12].

Another possible benefit of the intake of FAs lies on the prevention of atrial fibrillation. Even though different results were found among studies, EPA and DHA may take part on the structural remodeling of the atrium. A prospective population-based study among individuals $\geq 65$ years of age showed a lower atrial fibrillation risk after the consumption of grilled or baked fish. As this elderly group (elderly meaning patients $\geq 65$ years) typically presents with frequent underlying cardiovascular disorders that result in structural remodeling of the atrium, it is believed that this specific cause of atrial fibrillation is the one that may benefits from fatty acids supplementation [10].

Despite the established benefits of the fish intake on cardiovascular disorders, there is no evidence regarding the use of EPA/DHA supplementation (capsules of oil fish) in prevention of heart attack, stroke, cardiovascular disease in general, sudden death and overall mortality in general population or among people with diagnosed cardiovascular disease [13]-[15]

\subsection{Cognitive Health}

In order to be possible the correct transmission of impulses, it is mandatory that the neuronal membrane allows a suitable exchange of ions between its inner and outer walls. That mechanism is controlled by the membrane's fluidity. In peripheral membranes, this fluidity is influenced by factor such as dietary fatty acids, alcohol, aging, anesthetic and psychoactive drugs, thyroxin, and iron overload; in the brain, it is influenced by dietary fatty acids - in particular PUFAs, as well as anesthetic drugs, aging and levels of cholesterol. Thereby, a number of factors can regulate the neuronal transmission [16] [17].

Furthermore, free FAs are also capable of adjusting membrane proteins so that ion channels can adapt to the passage of neuronal information along the axon. This mechanism is also influenced by lipid metabolites and phospholipids. To play a role in the cognitive and biochemical functions, EFAs' levels are critical, along with the ratio between n-3 and n-6 FAs: while n-3 FA increases the level and receptor's density of dopamine, both n-3 and n-6 FAs decrease cholesterol levels through different modes of action. All these PUFAs are able to alter membrane fluidity, membrane receptor formation and function, membrane signaling, and surface membrane enzyme activity [16].

Incipient evidence suggests that fish consumption and the intake of EPA and DHA might be able to protect against dementia and Alzheimer disease-both featured by a progressive degenerative cognitive decline. Two main actions might explain the possible benefits associated with n-3 FAs: firstly, their anti-inflammatory and cardiovascular protective effects, by reducing the risk of atherothrombotic complications and preventing a subsequent cognitive decline; secondly, improval of the composition of cell membranes, thus stimulate the development and regeneration of nerve cells [11] [17]. 


\subsection{Pregnancy and Infancy}

During pregnancy and lactation, there is an intense mobilization of PUFA for the synthesis of fetal and infant tissue. The brain and the nervous system, being rich in $n-3$, take a large part of that amount. The basal requirements of EFA corresponds to 3\% of total calories, which may rise to $4.5 \%$ during pregnancy and $5 \%-7 \%$ during lactation. A correlation between low birth weight and low intake of LA and n-3 FA has been shown in previous studies [18].

McNamara et al. reported the first documented case of human n-3 deficiency in 1982. In this case report, a six-year-old girl maintained for 5 months on an ALA-deficient parenteral nutrition, showed a 17\% reduction in plasma DHA concentrations relative to age-matched controls. She then developed dermatitis and neurological symptoms, including neuropathy, blurred vision, and psychological disturbances, which were normalized as soon as the parenteral nutritional preparation was replaced with an ALA-fortified preparation [17].

Boys aged 6 to 12 years [with and without attention deficit/hyperactivity disorder (ADHD)] with lower plasma total n-3 showed increased behavior problems, learning, and health disturbances than those with higher levels of total n-3 FA. It was also verified that dietary supplementation with n-3 FAs reduces symptoms of ADHD, both for individuals with ADHD and also for children with a normal development [19].

Patients with Autistic Spectrum Diseases (ASD) also presented lower levels of n-3 when compared to controls. Even though the reasons for this association remain unclear, it is known that the neural tissue requires high concentrations of DHA, suggesting its participation on the growth and development of the human brain. The use of supplementary DHA as an alternative medical treatment, however, has not proven its safety and efficacy so far [20].

\subsection{Eye Health}

Some studies suggest the possible benefits of the EFAs intake on eye diseases, such as dry eye syndrome, age-related macular degeneration (AMD), and cataract. However, there is still insufficient evidence to assume premature conclusions, and further research is needed [21]-[23].

A randomized controlled trial conducted in subjects with the dry eye syndrome showed that a dietary intervention with n-3 FA acid improved the symptoms and clinical markers of dry eyes [24]. In an observational study, authors showed that the consumption of canned tuna fish or more than four fish servings per week each played a protective role against AMD; however, other types of oily fish well known to have high concentrations of EPA and DHA (sardines, mackerel) failed to show a similar result [25].

\section{N-6/n-3 Ratio Values and Recommendations}

The n- 6 and n-3 FA compete for the enzymes involved in the desaturation and chain elongation reactions. Although these enzymes have greater affinity for the n-3 family acids, conversion of ALA is strongly influenced by dietary LA levels. Thus, the ratio of the daily intake of food sources of n-6 and n-3 FA is important in human nutrition, resulting in several recommendations that have been established by authors and health agencies in different countries [2].

The values listed in Table 1 show the trend of convergence in n-6/n-3 FA, which range from 4:1 to 10:1. Some authors have recommended the ratio of 2:1 to 3:1 by allowing a greater conversion of ALA to DHA, which reaches its maximum value around 2.3:1. Thus, the ratios between 2:1 and 4:1 are most important for people with eating habits that result in a low intake of EPA and DHA. Moreover, based diets ratios n-6/n-3 of less than 1:1 are not recommended to inhibit the conversion of linoleic acid into very long chain (VLC) PUFA.

WHO $=$ World Health Organization; FAO $=$ Food and Agriculture Organization; SRC $=$ Scientific Review Committee; NCM = Nordic Council of Ministeers. Adapted from Martin, M.A. [2].

It is estimated that the ratio $n-6 / n-3$ in the diet of people who lived in the run up industrialization was around 1:1 to $2: 1$, due to the abundant consumption of vegetables and seafood products containing n-3 FAs. With industrialization, there was a progressive increase in this ratio, mainly due to the production of refined oils derived from oil varieties high in AL and decreased intake of fruits and vegetables, resulting in diets with inadequate amounts of $\mathrm{n}-3$. In the past decades it has been found that in many countries, the average intake of fatty acids results in the n-6/n-3 relationships are between 10:1 to 20:1, occurring records of up to 50:1 [2] [26].

The International Society for the Study of Fatty Acids and Lipids (ISSFAL) issued specific recommendations 
Table 1. Values recommended for the ratio between n-6 and n-3 FA in the diet.

\begin{tabular}{|c|c|}
\hline Country or Institution & $n-6 / n-3$ ratio \\
\hline Canada & $4: 1-10: 1$ \\
\hline USA & $2: 1-3: 1$ \\
\hline USA & $4: 1$ \\
\hline France & $5: 1$ \\
\hline Japan & $2: 1-4: 1$ \\
\hline Sweden & $5: 1$ \\
\hline WHO/FAO & $5: 1-10: 1$ \\
\hline
\end{tabular}

about the intake of PUFA, which follow: 1) 2\% of total daily energy intake from LA; 2) $0.7 \%$ of total daily energy intake from ALA; and 3) for cardiovascular health, a minimum intake of EPA and DHA combined of $500 \mathrm{mg} / \mathrm{d}$ [27]. The US Institute of Medicine (IOM) recommends for men and women $\geq 18$ years, respectively: $\sim 17 \mathrm{~g}$ and $12 \mathrm{~g}$ /day of n-6; 1.6 g and $1.1 \mathrm{~g}$ /day of n-3. For men and women over 65 years of age, the US IOM recommendations are, respectively, $\sim 14 \mathrm{~g}$ and $11 \mathrm{~g} /$ day of $\mathrm{n}-6 ; \sim 1.6 \mathrm{~g}$ and $1.1 \mathrm{~g} /$ day of $\mathrm{n}-3$ [28].

\section{Trans Fatty Acids: Time for a Ban}

Trans fatty acids (TFA) have been increasingly regarded as a clear health risk [29]. They are unsaturated FA with at least one unsaturated, non-conjugated double bond in the trans (rather than the typical cis) configuration. Small amounts of trans fat acids are found in natura in meat and dairy products, but the main source of TFA is food processing. Partial hydrogenation converts vegetable oils into semisolid fats, which also makes food preparation easier, improving flavor and texture [30].

Randomized clinical trials and observational studies have provided consonant evidences regarding a strong association of the consumption of partially hydrogenated oils with an increase of cardiovascular risk factors and coronary heart disease [30] [31]. The PAHO/WHO Task Force (2007) on "Trans Fat Free Americas" recommended that industrial TFA should be limited to less than $2 \%$ of total fat in vegetable oils and margarines, and less than 5\% for other foods [32]. A current example of such development is FDA's recent statement defining the ban of trans fats by food industries in the United States within 3 years [33]. Therefore, it is time to promote an effective international intervention to restrict the use of TFA in foods.

\section{Conclusions}

Essential fatty acids show increasing available evidence of its benefits in human health. Its use is focused on the prevention of a large body of chronicle diseases, especially regarding reduction of cardiovascular risk, cognitive health and eye health problems. Pregnancy and childhood are also life cycles in which fatty acids may be also beneficial, as suggested by recent studies.

Fatty fishes are the most important natural source of EPA and DHA. The balance between n- 6 and n-3 in the diet seems to be crucial for a better human health. Industrialization brought a disbalance in this intake. The current recommendation for populations is to seek the ratio of 2:1 to 3:1 in the western diet, thus allowing a greater conversion of ALA to DHA and enhancing its possible beneficial effects.

Recently a key determination was raised regarding the possibility of a ban on the production and consumption of trans fatty acids. These are strongly associated with cardiovascular risk, according to available scientific evidence and the findings of expert scientific panels. FDA considers now their consumption as "unsafe", and decided this June 2015 to ban trans fat acids use in processed foods in the United States until mid 2018. This decision should be encouraged and followed by other public health authorities, especially by those of countries in which obesity and diabetes grow as hazardous epidemics. This is a low cost, highly effective measure that could reduce the alarming numbers of cardiovascular disease among patients. 


\section{Acknowledgements}

The authors would like to thank IPEMED Brazil for supporting continuous research towards a better medical education in Brazil and abroad.

\section{References}

[1] Suárez-Mahecha, H., Francisco, A., Beirão, L.H., Block, J.M,, Saccol, A. and Pardo-Carrasco, S. (2020) Importance of oily Acids Present Poliinsaturados in Fishes of Cultivation and of Natural Environment for the Human Nutrition. Report of the Institute of Fishing, Sao Paulo, 28, 101-110.

[2] Martin, M.A., Almeida, V.V., Ruiz, M.R., Visentainer, J.E.L., Matshushita, M., Souza, N.E., et al. (2006) Omega-3 and Omega-6 Polyunsaturated Fatty Acids: Importance and Occurrence in Foods. Revista de Nutrição, 19, 761-770.

[3] Sander, A.B.T. (2000) Polyunsaturated Fatty Acids in the Food Chain in Europe. American Journal of Clinical Nutrition, 71, 176S-178S.

[4] Martins, M.B., Suaiden, A.S., Piotto, R.F. and Barbosa, M. (2008) Properties of Omega-3 Polyunsaturated Fatty Acids Obtained of Fish Oil and Flaxseed Oil. Revista do Instituto de Ciências da Saúde, 26, 153-156.

[5] Kus, M.M.M. and Mancini-Filho, J. (2010) Funções Plenamente Reconhecidas de Nutrientes: Ácidos Graxos. International Life Sciences Institute do Brasil, 17, 3-18.

[6] Burdge, G.C. and Calder, P.C. (2005) Conversion of Alpha-Linolenic Acid to Longer-Chain Polyunsaturated Fatty Acids in Human Adults. Reproduction Nutrition Development, 45, 581-597. http://dx.doi.org/10.1051/rnd:2005047

[7] Brenna, J.T, Salem Jr., N., Sinclair, A.J. and Cunnane, S.C. (2009) Alpha-Linolenic Acid Supplementation and Conversion to n-3 Long-Chain Polyunsaturated Fatty Acids in Humans. Prostaglandins, Leukotrienes and Essential Fatty Acids, 80, 85-91. http://dx.doi.org/10.1016/j.plefa.2009.01.004

[8] Simopoulos, A.P. (1999) Essential Fatty Acids in Health and Chronic Disease. American Journal of Clinical Nutrition, 70, 560S-569S.

[9] Kris-Etherton, P.M., Harris, W.S. and Appel, L.J. (2002) American Heart Association. Nutrition Committee. Fish Consumption, Fish Oil, Omega-3 Fatty Acids, and Cardiovascular Disease. Circulation, 106, 2747-2757. http://dx.doi.org/10.1161/01.CIR.0000038493.65177.94

[10] Saravanan, P., Davidson, N.C., Schmidt, E.B. and Calder, P.C. (2010) Cardiovascular Effects of Marine Omega-3 Fatty Acids. Lancet, 375, 540-550. http://dx.doi.org/10.1016/S0140-6736(10)60445-X

[11] American Heart Association Nutrition Committee, Lichtenstein, A.H., Appel, L.J., Brands, M., Carnethon, M., Daniels, S., et al. (2006) Diet and Lifestyle Recommendations Revision 2006: A Scientific Statement from the American Heart Association Nutrition Committee. Circulation, 114, 82-96. http://dx.doi.org/10.1161/CIRCULATIONAHA.106.176158

[12] Bays, H.E., Tighe, A.P., Sadovsky, R. and Davidson, M.H. (2008) Prescription Omega-3 Fatty Acids and Their Lipid Effects: Physiologic Mechanisms of Action and Clinical Implications. Expert Review of Cardiovascular Therapy, 6, 391-409. http://dx.doi.org/10.1586/14779072.6.3.391

[13] Enns, J.E., Yeganeh, A., Zarychanski, R., Abou-Setta, A.M., Friesen, C., Zahradka, P., et al. (2014) The Impact of Omega-3 Polyunsaturated Fatty Acid Supplementation on the Incidence of Cardiovascular Events and Complications in Peripheral Arterial Disease: A Systematic Review and Meta-Analysis. BMC Cardiovascular Disorders, 4, 70. http://dx.doi.org/10.1186/1471-2261-14-70

[14] Wen, Y.T., Dai, J.H. and Gao, Q. (2014) Effects of Omega-3 Fatty Acid on Major Cardiovascular Events and Mortality in Patients with Coronary Heart Disease: A Meta-Analysis of Randomized Controlled Trials. Nutrition, Metabolism and Cardiovascular Diseases, 24, 470-475. http://dx.doi.org/10.1016/j.numecd.2013.12.004

[15] Rizos, E.C., Ntzani, E.E., Bika, E., Kostapanos, M.S. and Elisaf, M.S. (2012) Association between Omega-3 Fatty Acid Supplementation and Risk of Major Cardiovascular Disease Events: A Systematic Review and Meta-Analysis. JAMA, 308, 1024-1033. http://dx.doi.org/10.1001/2012.jama.11374

[16] Yehuda, S., Rabinovitz, S. and Mostofsky, D.I. (1999) Essential Fatty Acids Are Mediators of Brain Biochemistry and Cognitive Functions. Journal of Neuroscience Research, 56, 565-570. http://dx.doi.org/10.1002/(SICI)1097-4547(19990615)56:6<565::AID-JNR2>3.0.CO;2-H

[17] McNamara, R.K. and Carlson, S.E. (2006) Role of Omega-3 Fatty Acids in Brain Development and Function: Potential Implications for the Pathogenesis and Prevention of Psychopathology. Prostaglandins, Leukotrienes and Essential Fatty Acids, 75, 329-349. http://dx.doi.org/10.1016/j.plefa.2006.07.010

[18] Holman, R.T, Johnson, S.B. and Ogburn, P.L. (1991) Deficiency of Essential Fatty Acids and Membrane Fluidity during Pregnancy and Lactation. Proceedings of the National Academy of Sciences of the United States of America, 88, 4835-4839. http://dx.doi.org/10.1073/pnas.88.11.4835 
[19] Bos, D.J., Oranje, B., Veerhoek, E.S., Van Diepen, R.M., Weusten, J.M., Demmelmair, H., et al. (2015) Reduced Symptoms of Inattention after Dietary Omega-3 Fatty Acid Supplementation in Boys with and without Attention Deficit/ Hyperactivity Disorder. Neuropsychopharmacology, 19 March 2015. Epub ahead of print.

[20] Bent, S., Bertgolio, K. and Hendren, R.L. (2009) Omega-3 Fatty Acids for Autistic Spectrum Disorder: A Systematic Review. Journal of Autism and Developmental Disorders, 39, 1145-1154. http://dx.doi.org/10.1007/s10803-009-0724-5

[21] Chew, E.Y., Clemons, T.E., SanGiovanni, J.P., Danis, R., Ferris, F.L., Elman, M., et al. (2013) Lutein + Zeaxanthin and Omega-3 Fatty Acids for Age-Related Macular Degeneration: The Age-Related Eye Disease Study 2 (AREDS2) Randomized Clinical Trial. JAMA, 309, 2005-2015. http://dx.doi.org/10.1001/jama.2013.4997

[22] Hodge, W., Barnes, D., Schachter H.M., Pan, Y., Lowcock, E.C., Zhang, L., et al. (2005) Effects of Omega-3 Fatty Acids on Eye Health. Evidence Report/Technology Assessment No. 117, US Department of Health and Human Services, Archive Agency for Healthcare Research and Quality, Evidence-Based Practice Program.

[23] Suzuki, H., Morikawa, Y. and Takahashi, H. (2001) Effect of DHA Oil Supplementation on Intelligence and Visual Acuity in the Elderly. World Review of Nutrition and Dietetics, 88, 68-71. http://dx.doi.org/10.1159/000059767

[24] Bhargava, R., Kumar, P., Kumar, M., Mehra, N. and Mishra, A. (2013) A Randomized Controlled Trial of Omega-3 Fatty Acids in Dry Eye Syndrome. International Journal of Ophthalmology, 6, 811-816.

[25] Ouchi, M., Ikeda, T., Nakamura, K., Harino, S. and Kinoshita, S. (2002) A Novel Relation of Fatty Acid with Age-Related Macular Degeneration. Ophthalmologica, 216, 363-367. http://dx.doi.org/10.1159/000066178

[26] Simopoulos, A.P. (2008) The Omega-6/Omega-3 Fatty Acid Ratio, Genetic Variation, and Cardiovascular Disease. Asia Pacific Journal of Clinical Nutrition, 17, 131-134.

[27] ISSFAL. International Society for the Study of Fatty Acids and Lipids. http://www.issfal.org/statements/pufa-recommendations

[28] National Research Council (2005) Dietary Reference Intakes for Energy, Carbohydrate, Fiber, Fat, Fatty Acids, Cholesterol, Protein, and Amino Acids (Macronutrients). The National Academies Press, Washington DC.

[29] WHO (World Health Organization) (2011) Global Status Report on Noncommunicable Diseases 2010. http://www.who.int/nmh/publications/ncd report full en.pdf

[30] Mozaffarian, D., Katan, M.B., Ascherio, A., Stampfer, M.J. and Willett, W.C. (2006) Trans Fatty Acids and Cardiovascular Disease. New England Journal of Medicine, 354, 1601-1613. http://dx.doi.org/10.1056/NEJMra054035

[31] Mozaffarian, D., Micha, R. and Wallace, S. (2010) Effects on Coronary Heart Disease of Increasing Polyunsaturated Fat in Place of Saturated Fat: A Systematic Review and Meta-Analysis of Randomized Controlled Trials. PLoS Medicine, 7, e1000252. http://dx.doi.org/10.1371/journal.pmed.1000252

[32] PAHO/WHO Task Force (2007) Trans Fats Free Americas Conclusions and Recommendations. Pan American Health Organization, Washington DC. http://www.sld.cu/galerias/pdf/sitios/diabetes/final paho who task force conclusions may 17 07.pdf

[33] McCarthy, M. (2013) US Moves to Ban Trans Fats. BMJ, 347, Article ID: f6749. http://dx.doi.org/10.1136/bmj.f6749 